\title{
Dermatology Procedural and Surgical Skills Workshop for Medical and Physician Assistant Students*
}

\author{
Julie Martin, Sheila Z. Jalalat, Richard F. Wagner ${ }^{\#}$ \\ The University of Texas Medical Branch, Galveston, USA. \\ Email: "rfwagner@utmb.edu \\ Received October 22 ${ }^{\text {nd }}, 2013$; revised November $16^{\text {th }}, 2013$; accepted November $23^{\text {rd }}, 2013$ \\ Copyright (C) 2013 Julie Martin et al. This is an open access article distributed under the Creative Commons Attribution License, \\ which permits unrestricted use, distribution, and reproduction in any medium, provided the original work is properly cited.
}

\begin{abstract}
Background: Evidence indicating the limited amount of hands-on experience in the current era of medical training has raised concern regarding students' development and potential deficiencies in the performance of basic procedural skills. Studies have demonstrated the value of surgical workshops for medical students; however evaluation of improved student performance during future clerkships or residencies has yet to be assessed. We initiated and evaluated a resident-led surgical skills workshop for students through the Department of Dermatology. Methods: Participants received instructions on surgical tools/techniques followed by hands-on practice. Anonymous surveys administered to 24 medical and physician assistant students assessed their skill level, confidence level, and likelihood of using surgical skills in future practice pre- and post-workshop using a 1 - 5 Likert scale. Overall experience was also assessed. Non-parametric bivariate tests were used for analysis to account for non-normal distribution of the data. Results: There was a statistically significant change in skill $(p=0.0001)$ and confidence $(p=0.0001)$ level post workshop. There was no significant difference in utility. There were also no statistically significant differences based on the year of medical student training, medical student versus physician assistant student responses, or number of procedures performed prior to the workshop. Estimated cost per participant was \$5.65. Conclusions: Research supports our finding that workshop learning experiences increase students' ability to perform common procedural skills, their confidence, and desire to practice such skills. Further studies are necessary to determine the impact of these skills workshops on long-term clinical performance in future clerkships and residencies.
\end{abstract}

Keywords: Procedural Skills; Workshop; Dermatology; Residents; Medical Students

\section{Introduction}

Recent studies have shown trends towards an increasingly limited amount of hands-on experience for medical students in the current era of medical training [1-10]. This observation increases concern regarding students' development and potential inadequacies in basic skills performance. The commonest reported obstacles to teaching basic technical skills include faculty and resident time constraints, medicolegal concerns such as malpractice liability, costs, students' safety including disease transmission, and patient preference [11]. Given the expanding role of multiple surgical procedures in dermatology clinical practice, sources highlight that resident training in procedural skills must be continually assessed

*Presented in part at the Semiannual Meeting of the Dermatology Teachers Exchange Group, Chicago, Illinois, September 27, 2013.

\#Corresponding author. to keep pace with changes in the specialty [12]. Recent evidence suggests that residents as teacher-trainers improve resident attitudes and perceptions toward teaching as well as their theoretical knowledge, skills, and teaching behavior [11,13]. Furthermore, it has also been shown that medical students ascribe one-third of their clinical education to the teaching of interns and residents and consider them to be important role models and mentors [14-18]. Training opportunities during clinical years have been shown to promote skill instruction when they are most likely to contribute to accelerating clinical learning [19]. In addition, student experiences, such as acting internships, have also been designed to provide valuable practice in learning procedural skills [20]. Given the information gathered from recent literature, we decided to show our recent experience with resident-led surgical skills workshops for medical and physician assistant stu- 
dents through the Department of Dermatology.

\section{Background}

Recent Accreditation Council for Graduate Medical Education requirements mandate documentation of competency in procedural skills [21]. In addition, it has been reported that little change has occurred in the teaching and evaluation of technical skills in half of US medical schools since 1993 [11]. Results from medical student surveys demonstrated the value of incorporating preparatory surgical workshops in the medical school curriculum [1,22]. This suggests the need for further research to determine if such workshops improve future student performances during subsequent training. Over the past 14 years, one institution reported that the number of procedural workshops have increased from 11 to 31, and currently involve clerkship faculty from family medicine, internal medicine, and pediatrics [20]. We retrospectively reviewed the medical literature using PubMed, searching the terms procedural skills, workshop, dermatology, residents, and student. Subsequently, several articles describing models for procedural skill workshops were retrieved (Table 1).

\section{Materials and Methods}

Fifteen medical students and nine physician assistant students participated in skills workshops during the 20122013 academic year. The students in the study comprised of students enrolled in any of the one-month dermatology electives and Dermatology Interest Group members. There were a total of six workshops held throughout the year. The workshop started with an anonymous preworkshop questionnaire (Appendix 1). This was followed by a ten-minute PowerPoint presentation about how to set up for biopsy, basic surgical instruments, safety precautions, sutures, and suturing techniques. After the presentation, hands-on practice with resident supervision began with skills including injection of local anesthetic, tangential and punching biopsies using pig feet, suturing/wound closure and knot tying. The workshop concluded with an anonymous post-workshop questionnaire (Appendix 2). The total time of the workshop was 90 minutes. Internal departmental educational activities are not subject to Institutional Review Board review.

In the anonymous surveys administered for the pre and post skills workshop, respondents were asked to assess their skill level, confidence level, and likelihood of use of surgical skills in future practice (utility). The results were recorded using 1 - 5 Likert scales. Respondents were also asked to assess overall experience after the surgical skills workshop using a 1 - 5 Likert scale. The Wilcoxon Signed Rank non-parametric bivariate test was used to compare the medians for pre- vs. post-workshop survey
Table 1. Procedural skills teaching models.

\begin{tabular}{|c|c|}
\hline Model & Description \\
\hline $\begin{array}{l}\text { Theory-based } \\
\text { method [23] }\end{array}$ & $\begin{array}{l}\text { Four-step method: } \\
\text { 1) Demonstration } \\
\text { 2) Deconstruction } \\
\text { 3) Formulation } \\
\text { 4) Performance }\end{array}$ \\
\hline $\begin{array}{l}\text { Modem } \\
\text { instructional } \\
\text { design [24] }\end{array}$ & $\begin{array}{l}\text { Nine events of instruction approach: } \\
\text { 1) Getting attention } \\
\text { 2) Informing the learner of the objectives } \\
\text { 3) Stimulating recall of prerequisite learning } \\
\text { 4) Presenting stimulus material } \\
\text { 5) Providing learner guidance } \\
\text { 6) Eliciting the performance } \\
\text { 7) Providing feedback and performance correction } \\
\text { 8) Assessing performance } \\
\text { 9) Enhancing retention and transfer of knowledge } \\
\text { 10) Enhancing retention and transfer of knowledge }\end{array}$ \\
\hline $\begin{array}{l}\text { Prerequisite } \\
\text { knowledge [25] }\end{array}$ & $\begin{array}{l}\text { Ensuring prerequisite knowledge using an } \\
\text { Extended Match Questionnaire (EMQ) before } \\
\text { proceeding to practical skills }\end{array}$ \\
\hline $\begin{array}{l}\text { Microskills and } \\
\text { station-based } \\
\text { deconstructed [26] }\end{array}$ & $\begin{array}{l}\text { Training based on three concepts: } \\
\text { 1) Skill } \\
\text { 2) Microskill actions derived from deconstruction } \\
\text { of each skill } \\
\text { 3) Tuition in structured educational stations }\end{array}$ \\
\hline $\begin{array}{l}\text { Microskills with } \\
\text { learning } \\
\text { preference [27] }\end{array}$ & $\begin{array}{l}\text { Categorizing learners as visual, auditory, } \\
\text { and tactile learners for specialized } \\
\text { procedural skills workshop }\end{array}$ \\
\hline
\end{tabular}

questions. The Kruskal Wallis non-parametric bivariate test was used to compare the medians for pre- vs. postworkshop survey questions specifically by year and number of procedures. The Wilcoxon Mann-Whitneynon-parametric bivariate test was used to compare responses by the medical and physician assistant students. These tests were used to account for non-normal distribution of the data using SAS software, version 9.3. The supplies and estimated cost for each participant for the workshop was $\$ 5.65$ (Table 2).

\section{Results}

Results using the Wilcoxon Signed Rank Test showed a statistically significant change in skill $(p=0.0001)$ and confidence level ( $p=0.0001$ ) post workshop (Table 3). There was no significant difference in utility and there were no statistically significant differences based on the year of training, medical vs. physician student responses, or number of procedures performed prior to the workshop. More medical students (67\%) had previously participated in a surgical skills workshop than physician assistant students (56\%).

\section{Conclusions}

There was a statistically significant change in student 
Table 2. Supplies and estimated cost per student.

\begin{tabular}{cc}
\hline Pig foot & $\$ 1.00$ \\
Tomato & $\$ 0.50$ \\
Marshmallow & $\$ 0.05$ \\
Number 15 blade & $\$ 0.31$ \\
Derma blade & $\$ 1.28$ \\
Punch biopsy & $\$ 1.67$ \\
1 Prolene suture & $\$ 5.48^{*}$ \\
1 Vicryl suture & $\$ 8-11.00^{*}$ \\
Plastic bag (used as placemat) & $\$ 0.15$ \\
Antiseptic wipe & $\$ 0.09$ \\
Local anesthesia (2\% lidocaine with epinephrine) & $\$ 0.15^{*}$ \\
Non-sterile gloves & $\$ .20$ \\
1 cc syringe & $\$ 0.30$ \\
30 G $\times 1 / 2$ needle & $\$ 0.10$ \\
Estimated total cost per participant & $\$ 5.65$ \\
\hline
\end{tabular}

*Expired supply item, cost not totaled.

Table 3. Comparison of medians for pre- vs. post-anonymous survey questions (Wilcoxon signed rank test).

\begin{tabular}{ccccc}
\hline & $\begin{array}{c}\text { Pre }(\boldsymbol{n}=\mathbf{2 4 )} \\
\text { Median (IQR) }\end{array}$ & $\begin{array}{c}\text { Post }(\boldsymbol{n}=\mathbf{2 4 )} \\
\text { Median (IQR) }\end{array}$ & $\begin{array}{c}\text { Change } \\
\text { Median (IQR) }\end{array}$ & $\boldsymbol{p}$-value \\
\hline Skill & $2(1-3)$ & $4(3-4)$ & $1(1-2)$ & 0.0001 \\
Confidence & $3(2-4)$ & $4(3-5)$ & $1(0-2)$ & 0.0001 \\
Utility & $5(5-5)$ & $5(5-5)$ & $0(0-0)$ & 1.000 \\
$\begin{array}{c}\text { Overall } \\
\text { Experience }\end{array}$ & & $5(5-5)$ & & \\
\hline
\end{tabular}

Legend: IQR (interquartile range).

skill level and confidence level post-workshop. Students unanimously expressed that the workshop was an overall good experience. Research supports our finding that workshop learning experiences increase students' ability to perform common procedural skills, their confidence, and their desire to practice such skills [20]. However, additional studies are necessary to determine the impact of these skills workshops on long-term procedural performance in future clerkships and residencies.

Limitations of our study include the small number of participants, not inquiring about the students' anticipated future career or specialty, and not comparing internal vs. visiting students. In the future, an alternative to pre- and post-self-surveys could be used, for example the 12-Step Performance Grading Instrument created by Wang et al. in order to measure the impact of the workshop using objective grading and documentation of competency. In addition, although pigs' feet have traditionally been used to teach procedural skills in dermatology, technology has allowed the development of additional simulators which could be considered in future workshops [21]. The need for improvement in procedural skills is evident in the literature and has been affirmed to be an important learning process, therefore, these workshops may be beneficial for specialties like dermatology [21].

\section{REFERENCES}

[1] J. J. Dehmer, K. D. Amos, T. M. Farrell, A. A. Meyer, W. P. Newton and M. O. Meyers, "Competence and Confidence with Basic Procedural Skills: The Experience and Opinions of Fourth-Year Medical Students at a Single Institution,” Academic Medicine, Vol. 88, No. 5, 2013, pp. 682-687. http://dx.doi.org/10.1097/ACM.0b013e31828b0007

[2] L. M. Lippa, J. Boker, A. Duke and A. Amin, "A Novel 3-Year Longitudinal Pilot Study of Medical Students' Acquisition and Retention of Screening Eye Examination Skills,” Ophthalmology, Vol. 113, No. 1, 2006, pp. 113133. http://dx.doi.org/10.1016/j.ophtha.2005.09.003

[3] S. Mangione, "Cardiac Auscultory Skills of Physiciansin-Training: A Comparison of Three English-Speaking Countries,” American Journal of Medicine, Vol. 110, No. 3, 2001, pp. 210-216. http://dx.doi.org/10.1016/S0002-9343(00)00673-2

[4] E. S. Holmboe, "Faculty and the Observation of Trainees' Clinical Skills: Problems and Opportunities,” Academic Medicine, Vol. 79, No. 1, 2004, pp. 16-22.

http://dx.doi.org/10.1097/00001888-200401000-00006

[5] D. M. Elnicki and M. J. Fagan, "Medical Students and Procedural Skills," American Journal of Medicine, Vol. 114, No. 4, 2003, pp. 343-345.

http://dx.doi.org/10.1016/S0002-9343(03)00073-1

[6] S. A. Engum, "Do You Know Your Students' Basic Clinical Skills Exposure?” American Journal of Surgery, Vol. 186, No. 2, 2003, pp. 175-181. http://dx.doi.org/10.1016/S0002-9610(03)00182-X

[7] J. Vukanovic-Criley, S. Criley, C. M. Warde, et al., "Competency in Cardiac Examination Skills in Medical Students, Trainees, Physicians, and Faculty,” Archives of Internal Medicine, Vol. 166, No. 6, 2006, pp. 610-616. http://dx.doi.org/10.1001/archinte.166.6.610

[8] C. Ortiz-Neu, J. Tenenbaum, C. A. Walters and J. A. Colliver, "Error Patterns of 3rd-Year Medical Students on the Cardiovascular Examination,” Teaching and Learning in Medicine, Vol. 13, No. 4, 2001, pp. 161-166. http://dx.doi.org/10.1207/S15328015TLM1303_5

[9] L. Wilkerson and M. Lee, “Assessing Physical Examination Skills of Senior Medical Students: Knowing How versus Knowing When,” Academic Medicine, Vol. 78, No. 10, 2003, pp. S30-S32. http://dx.doi.org/10.1097/00001888-200310001-00010

[10] N. L. York, A. H. Niehaus, S. J. Markwell and J. R. Folse, "Evaluation of Students' Physical Examination Skills during Their Surgery Clerkship," American Journal of Sur- 
gery, Vol. 177, No. 3, 1999, pp. 240-243. http://dx.doi.org/10.1016/S0002-9610(99)00005-7

[11] C. W. Sanders, J. C. Edwards and T. K Burdenski, “A Survey of Basic Technical Skills of Medical Students," Academic Medicine, Vol. 79, No. 9, 2004, pp. 873-875. http://dx.doi.org/10.1097/00001888-200409000-00013

[12] E. H. Lee, K. S. Nehal, S. W. Dusza, E. K. Hale and V. J. Levine, "Procedural Dermatology Training during Dermatology Residency: A Survey of Third-Year Dermatology Residents," Journal of the American Academy of Dermatology, Vol. 64, No. 3, 2011, pp. 475-483. http://dx.doi.org/10.1016/j.jaad.2010.05.044

[13] A. G. Hill, S. Srinivasa, S. J. Hawken, M. Barrow, S. E. Farrell, J. Hattie, et al., “ Impact of a Resident-As-Teacher Workshop on Teaching Behavior of Interns and Learning Outcomes of Medical Students," Journal of Graduate Medical Education, Vol. 4, No. 1, 2012, pp. 34-41. http://dx.doi.org/10.4300/JGME-D-11-00062.1

[14] M. Barrow, "Medical Students' Opinions of the House Officer as Teacher," Journal of Medical Education, Vol. 41, No. 8, 1966, pp. 807-810.

[15] R. G. Bing-You and M. S. Sproul, "Medical Students' Perceptions of Themselves and Residents as Teachers," Medical Teacher, Vol. 14, No. 2-3, 1992, pp. 133-138. http://dx.doi.org/10.3109/01421599209079479

[16] R. Remmen, J. Denekens, A. Scherpbier, I. Hermann, C. van der Vleuten, P. V. Roven, et al., "An Evaluation Study of the Didactic Quality of Clerkships,” Medical Education, Vol. 34, No. 6, 2000, pp. 460-464. http://dx.doi.org/10.1046/j.1365-2923.2000.00570.x

[17] S. K. De, P. K. Henke, G. Ailawadi, J. B. Dimick and L. M. Colletti, “Attending, House Officer, and Medical Student Perceptions about Teaching in the Third-Year Medical School General Surgery Clerkship,” Journal of the American College of Surgeons, Vol. 199, No. 6, 2004, pp. 932942. http://dx.doi.org/10.1016/j.jamcollsurg.2004.08.025

[18] L. D. Whittaker Jr, N. C. Estes, J. Ash and L. E. Meyer, "The Value of Resident Teaching to Improve Student Perceptions of Surgery Clerkships and Surgical Career Choices,” American Journal of Surgery, Vol. 191, No. 3, 2006, pp. 320-324. http://dx.doi.org/10.1016/j.amjsurg.2005.10.029

[19] E. C. Corbett, N. J. Payne, E. B. Bradley, K. L. Maughan, E. B. Heald and X. Q. Wang, "Enhancing Clinical Skills Education: University of Virginia School of Medicine's Clerkship Clinical Skills Workshop Program,” Academic Medicine, Vol. 82, No. 7, 2007, pp. 690-695.

http://dx.doi.org/10.1097/ACM.0b013e31806745b4

[20] J. B. Stephens, S. S. Raimer and R. F. Wagner, "The Dermatology Acting Internship,” Dermatology Online Journal, Vol. 17, No. 7, 2011, p. 9.

[21] T. S. Wang, J. L. Schwartz, D. J. Karimipour, J. S. Orringer, T. Hamilton and T. M. Johnson, "An Education Theory-Based Method to Teach a Procedural Skill," Archives of Dermatology, Vol. 140, No. 11, 2004, pp. 1357-1361.

http://dx.doi.org/10.1001/archderm.140.11.1357

[22] P. Johnson, C. Sly and P. H. Warnke, "Simulated Surgical Workshops Enhance Medical School Students’ Preparation for Clinical Rotation," Academy of Management Journal, Vol. 6, No. 2, 2013, pp. 79-87.

[23] M. Walker and R. Peyton, “Teaching in the Theatre,” In: J. W. R. Peyton, Ed., Teaching and Learning in Medical Practice, Manticore Publishers Europe, Rickmansworth, 1998.

[24] R. M. Gagne, “The Conditions of Learning," 4th Edition, Holt, Rinehart and Winston, New York, 1985.

[25] C. M. Reigeluth, M. D. Merrill and V. Bunderson, "The Structure of Subject Matter Content and Its Instructional Design Implications,” In: Merill and Mitchell Instructional Design Theory, Educational Technology Publications, Merill, 1994.

[26] S. M. Razavi, M. Karbakhsh, M. P. Khahi, S. Dabiran, S. Asefi, G. H Zaker Shahrak and A. R. B. Afrooz, "Station-Based Deconstructed Training Model for Teaching Procedural Skills to Medical Students: A Quasi-Experimental Study," Advances in Medical Education and Practice, Vol. 1, 2010, pp. 17-23.

[27] N. F. Barrett and B. Gopal, "Using the Five Microskills with Different Learning Preferences,” Family Medicine Journal, Vol. 40, No. 8, 2008, pp. 543-545. 


\section{Appendix 1. Anonymous Pre-Workshop Self-Survey}

\section{Year (MS1, MS2, MS3, MS4 or PAS):}

I have participated in a surgical skills workshop in the past

1) Yes

2) No

Regarding the number of biopsies and suturing opportunities, I have participated in:

1) $<5$

2) 5 - 10

3) $>10$

My skill level (biopsies, suturing, etc.) prior to participation in surgical skills workshop

1) No experience

2) Below average

3) Average

4) Excellent

I feel confident performing procedures under supervision during my clinical rotations

$\begin{array}{lllll}1 & 2 & 3 & 4 & 5\end{array}$

(1 = completely disagree, 2 = somewhat disagree, 3 = neutral, 4 = somewhat agree, 5 = completely agree)

I am likely to use surgical skills during a clinical rotation and in the future as a practitioner

$\begin{array}{lllll}1 & 2 & 3 & 4 & 5\end{array}$

(1 = completely disagree, 2 = somewhat disagree, 3 = neutral, 4 = somewhat agree, 5 = completely agree)

What would you like to learn/improve upon during this surgical skills workshop?

Legend: MS1 (first year medical student), MS2 (second year medical student), MS3 (third year medical student), MS4 (fourth year medical student), PAS (physician assistant student).

\section{Appendix 2. Anonymous Post-Workshop Self-Survey}

Year (MS1, MS2, MS3, MS4 or PAS):

My skill level (biopsies, suturing, etc.) improved after participation in surgical skills workshop

$\begin{array}{lllll}1 & 2 & 3 & 4 & 5\end{array}$

(1 = completely disagree, 2 = somewhat disagree, 3 = neutral, 4 = somewhat agree, 5 = completely agree)

I feel confident performing procedures under supervision during clinical rotations

$$
\begin{array}{lllll}
1 & 2 & 3 & 4 & 5
\end{array}
$$

(1 = completely disagree, 2 = somewhat disagree, 3 = neutral, 4 = somewhat agree, 5 = completely agree)

I am likely to use surgical skills during my clinical rotations and in the future as a practitioner

$\begin{array}{lllll}1 & 2 & 3 & 4 & 5\end{array}$

(1 = completely disagree, 2 = somewhat disagree, 3 = neutral, 4 = somewhat agree, 5 = completely agree)

Overall, the surgical skills workshop was a good experience

$$
\begin{array}{lllll}
1 & 2 & 3 & 4 & 5
\end{array}
$$

(1 = completely disagree, 2 = somewhat disagree, 3 = neutral, 4 = somewhat agree, 5 = completely agree)

How well were your goals met during this surgical skills workshop?

Any additions you would recommend for future surgical skills workshops?

\section{Additional comments:}

Legend: MS1 (first year medical student), MS2 (second year medical student), MS3 (third year medical student), MS4 (fourth year medical student), PAS (physician assistant student). 